\title{
A Comparison of Dexmedetomidine, Moxonidine and Alpha-Methyldopa Effects on Acute, Lethal Cocaine Toxicity
}

\author{
Murat Seyit ${ }^{1}$; Bulent Erdur ${ }^{1, *}$; Selim Kortunay ${ }^{2}$; Aykut Yuksel $^{3}$; Atakan Yilmaz $^{1}$; Mert Ozen $^{4}$; \\ Aykut Uyanik ${ }^{1}$; Onder Tomruk ${ }^{4}$; Ahmet Ergin ${ }^{5}$ \\ ${ }^{1}$ Department of Emergency Medicine, Medical Faculty, Pamukkale University, Denizli, Turkey \\ 2 Department of Pharmacology, Medical Faculty, Pamukkale University, Denizli, Turkey \\ 3 Department of Emergency Medicine, Goztepe Training and Research Hospital, Istanbul Medeniyet University, Istanbul, Turkey \\ ${ }_{4}^{4}$ Department of Emergency Medicine, Medical Faculty, Suleyman Demirel University, Isparta, Turkey \\ 5 Department of Emergency Medicine, Medical Faculty, Suleyman Demirel University, \\ *Corresponding Author: Bulent Erdur, Department of Emergency Medicine, Medical Faculty, Pamukkale University, Denizli, Turkey. Tel: +90-2582134812, E-mail: bulenterdur@hotmail.com
}

Received: March 5, 2014; Revised: June 2, 2014; Accepted: January 18, 2015

Background: The treatment of cocaine toxicity is an important subject for emergency physicians. We investigated the effects of dexmedetomidine, moxonidine and alpha-methyldopa on acute cocaine toxicity in mice.

Objectives: The aim of this study was to evaluate the effects of dexmedetomidine, moxonidine and alpha-methyldopa in a mouse model of acute cocaine toxicity.

Materials and Methods: We performed an experiment consisting of four groups ( $\mathrm{n}=25 \mathrm{each}$ ). The first group received normal saline solution, the second group received $40 \mu \mathrm{g} / \mathrm{kg}$ of dexmedetomidine, the third group received $0.1 \mathrm{mg} / \mathrm{kg}$ of moxonidineand the fourth group received $200 \mathrm{mg} / \mathrm{kg}$ of alpha-methyldopa, all of which were intraperitoneally administered 10 minutes before cocaine hydrochloride (105 $\mathrm{mg} / \mathrm{kg}$ ). All animals were observed for seizures (popcorn jumping, tonic-clonic activity, or a loss of the righting reflex) and lethality over the 30 minutes following cocaine treatment.

Results: The ratio of animals with convulsions was lower in all treated groups when compared to the control $(\mathrm{P}<0.001)$. Furthermore, $68 \%(n=17)$ of animals in the dexmedetomidine group, $84 \%(n=21)$ of the alpha-methyldopa group, $92 \%(n=23)$ of the moxonidine group and $100 \%(n=25)$ of the control group showed evidence of seizure activity $(P=0.009)$. Cocaine-induced lethality was observed in $12 \%(n=3)$ of the dexmedetomidine group, $48 \%(n=12)$ of the alpha-methyldopa group, $52 \%(n=13)$ of the moxonidine group, and $72 \%(n=18)$ of the control group $(\mathrm{P}<0.001)$. All treatments prolonged the time to seizure, which was longest in the dexmedetomidine group $(\mathrm{P}>0.05)$. In addition, the time to lethality was also longer in the same group $(\mathrm{P}<0.001)$.

Conclusions: The present study provides the first experimental evidence in support of dexmedetomidine treatment for cocaine-induced seizures. Premedication with dexmedetomidine reduces seizure activity in a mouse model of acute cocaine toxicity. In addition, while dexmedetomidine may be effective, moxonidine and alpha-methyldopa did not effectively prevent cocaine-induced lethality.

Keywords: Cocaine; Intoxication; Dexmedetomidine; Moxonidine; Alpha-Methyldopa

\section{Background}

Cocaine use can cause acute or chronic toxicity. This drug is responsible for approximately $5 \%$ to $10 \%$ of emergency department visits in the United States and it is also one of the most frequent causes of drug-related deaths (14). Cocaine is associated with many health complications that affect neurological, cardiovascular and gastrointestinal systems.

Cocaine increases the activity of dopamine, norepinephrine and serotonin, and in turn blocks the reuptake transporters for these monoamines in the central and peripheral nervous systems. In addition, cocaine modulates the endogenous opiate system. Acute cocaine poisoning causes neuronal hyperexcitability and can be fatal (3). The current treatment of choice for acute cocaine poisoning is the use of benzodiazepines (1), yet they do not directly interact with any of these neurotransmitter systems. Alpha 2 adrenoceptor ( $\alpha$ 2-AR) agonists may decrease the proportion of subjects reaching the end point of irreversible toxicity and may prolong survival after cocaine poisoning.

Central sympatholytic drugs, particularly $\alpha$ 2-AR agonists such as alpha-methyldopa, have been shown to reverse cocaine-induced increase in blood pressure and vascular resistance in experimental animals (5). Dexmedetomidine has clinically relevant sedative and analgesic properties and it is a highly selective $\alpha 2$-AR agonist. Although its precise mechanisms are unclear, recent studies have suggested that $\alpha$ 2-AR agonists have effects not only on noradrenergic systems but also on dopaminergic neurotransmitters as well (6-8). Certain areas of the brain, such as the nucleus accumbens (NAcc) (which is a mesolimbic dopaminergic area), are known to be ter-

Copyright (C) 2015, Iranian Red Crescent Medical Journal. This is an open-access article distributed under the terms of the Creative Commons Attribution-NonCommercial 4.0 International License (http://creativecommons.org/licenses/by-nc/4.0/) which permits copy and redistribute the material just in noncommercial usages, provided the original work is properly cited. 
minal projection sites for both noradrenergic and dopaminergic neurons. Moreover, the NAcc has been closely associated with some locomotor and other neurobehavioral effects of cocaine (9-11). Dexmedetomidine has been shown to markedly attenuate cocaine-induced coronary and systemic vasoconstriction in dogs (12) and it was found to be effective and safe in abolishing both the sympathoexcitatory and corresponding hemodynamic effects of cocaine in healthy cocaine-naive human subjects (13). Whittington et al. (14) speculated that dexmedetomidine may be potentially beneficial in controlling cocaine-induced central nervous system (CNS) excitotoxicity. These results suggest that the central sympatholytic and sedative properties of dexmedetomidine may make this drug a reasonable choice for acute cocaine poisoning treatment. There have been a number of case reports where other more traditional agents have failed, while dexmedetomidine has been successfully used to manage hypertension and CNS excitability from withdrawal of cocaine and opioids (15). Recently, similar results have also been reviewed related to poisoning with illicit substances (16).

The modulation of peripheral sympathetic activity by the CNS may involve various pathways, neurotransmitters and receptors. In addition to the $\alpha 2$-AR, the central imidazoline (I1) receptors, which are distributed throughout the CNS (17-20) and probably located in the nucleus reticularis lateralis of the medullary region, may also be involved in the central regulation of peripheral sympathetic activity. They could also act as a target of centrally-acting antihypertensives. Moxonidine is the prototype of such agents, and also has a low affinity for the $\alpha$ 2-AR. These data suggest that moxonidine may offer an alternative supplementary treatment for acute cocaine poisoning.

\section{Objectives}

Previously we reported the effects of pretreatment with etomidate, ketamine, phenytoin and phenytoin/midazolam on acute, lethal cocaine toxicity (21). Also recently we determined the effects of pretreatment with etomidate, ketamine, phenytoin, and phenytoin/midazolam on the same experimental model (22). The objective of this study was to determine whether pre-treatment with dexmedetomidine, moxonidine and alpha-methyldopa could attenuate cocaine toxicity. Our hypotheses were that these pre-treatments would decrease the proportion of animals reaching the end point of irreversible toxicity and would prolong the survival of cocaine-poisoned mice. If pre-treatment attenuates cocaine neurotoxicity, further studies can be performed to determine whether these drugs are effective once toxicity is established. To the best of our knowledge, this is the first trial that compares the efficacy of these three medications on cocaine induced seizures and mortality in this experimental pretreatment model.

\section{Materials and Methods}

\subsection{General}

The experimental study was designed to reach $80 \%$ power to detect a 30\% difference in lethality, assuming a control group survival of 30\%. Experiments were carried out on 100 mice weighing 25-30 g, which were divided to four groups, three experimental and one control $(\mathrm{n}=$ 25). All groups were selected by means of a randomized schedule. We used the simple random allocation strategy. The experimental procedures used in this study were approved by the Animal Bioethical Committee of Pamukkale University (01, 05, 2010; PAUHDEK-2010/002). The room temperature was maintained at $23 \pm 1^{\circ} \mathrm{C}$, and the humidity was kept at $50 \pm 5 \%$. All experiments were conducted between 2 and $6 \mathrm{pm}$ to minimize the circadian rhythm effect on the convulsion threshold. This research was conducted during January 2011.

\subsection{Drugs}

Dexmedetomidine (Precedex, Abbott Park, Illionis, U.S.A.), alpha-methyldopa (as a substance from Ibrahim Ethem, Istanbul, Turkey) and moxonidine (as a substance from Abbott Park, Illionis, USA) were used for this study. Mice ( $\mathrm{n}=25$ /group) were randomly assigned to one of four groups that received either normal saline solution, $40 \mu \mathrm{g} / \mathrm{kg}$ dexmedetomidine, $200 \mathrm{mg} / \mathrm{kg}$ alpha-methyldo$\mathrm{pa}$, or $4 \mathrm{mg} / \mathrm{kg}$ moxonidine. All drugs were intraperitoneally administered 10 minutes before the mice received cocaine hydrochloride $(105 \mathrm{mg} / \mathrm{kg})$.

\subsection{Main Outcome Measurements}

The primary measured outcomes in this study were seizure activity and lethality. Seizure activity was defined as convulsions, which were characterized by popcorn jumping, tonic-clonic activity, or righting reflex loss. Lethality was defined as the development of agonal respiration, seizures lasting longer than eight minutes, or an inability to ambulate for up to 30 minutes after cocaine administration.

The measured secondary outcomes were the seizure frequency ratio and the time to seizure. All outcomes were recorded by a single blinded observer, who observed the animals for 30 minutes. All animals were sacrificed at the end of the 30-minute experiment.

\subsection{Statistical Analysis}

Chi-square and Fisher's exact tests were used for comparisons when appropriate. A survival analysis was performed, and Kaplan-Meier survival curves were generated with a log rank. Results were considered statistically significant when $\mathrm{P}<0.05$. Data were analyzed with the Statistical Package for Social Sciences (SPSS) for Windows, Version 17.0. 
Seyit Met al.

Table 1. Distribution of Convulsions and Lethality Produced by Cocaine According to the Study Groups a

\begin{tabular}{lccccc}
\hline Variables & \multicolumn{3}{c}{ Study Groups } & Pvalue $^{\mathrm{b}}$ \\
\cline { 2 - 5 } & Alpha-Methyldopa & Moxonidine & Dexmedetomidine & \multicolumn{2}{c}{ Placebo $^{\mathrm{C}}$} \\
\hline Seizure & $21(84)$ & $23(92)$ & $17(68)$ & $25(100)$ & 0.009 \\
Lethality & $12(48)$ & $13(52)$ & $3(12)$ & $18(72)$ & $<0.001$ \\
\hline
\end{tabular}

${ }^{\mathrm{a}}$ Data are presented as No.(\%).

b Values come from the chi-squared test.

C Comes from Fisher exact test, values are less than 0.05 between dexmedetomidine and other medications in terms of lethality and seizure except for Alpha-Methyldopa in terms of lethality.

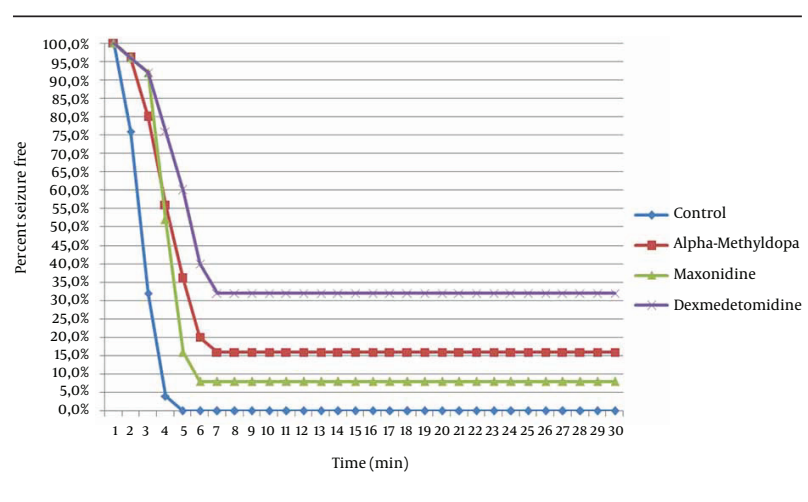

Figure 1. Kaplan-Meier Plot for Time to Seizures for Each Treatment Group

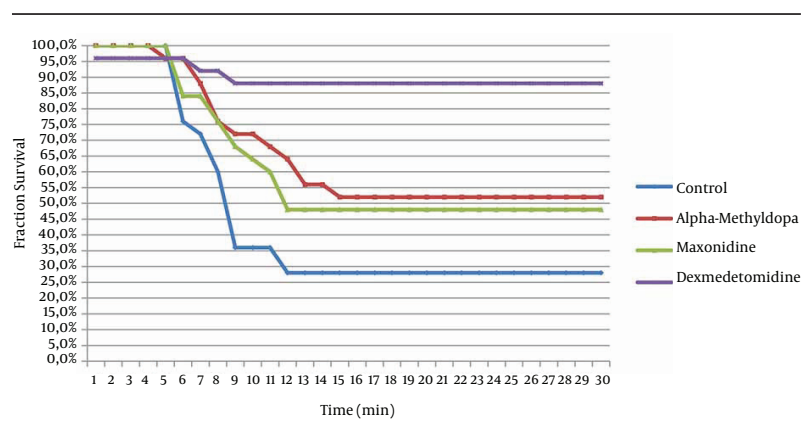

Figure 2. Kaplan-Meier Plot for Apparent Lethality for Each Treatment Group

\section{Results}

We observed that $86 \%$ of the mice had seizures after receiving $105 \mathrm{mg} / \mathrm{kg}$ of cocaine. More specifically, 68\% ( $\mathrm{n}=$ 17) of the animals in the dexmedetomidine group, $84 \%$ ( $n$ $=21)$ of the alpha-methyldopa group, $92 \%(n=23)$ of the moxonidine group and $100 \%(n=25)$ of the control group showed evidence of seizure activity $(\mathrm{P}=0.009)$. The ratio of animals with seizures was significantly lower in the dexmedetomidine (68\%) group in comparison to the con$\operatorname{trol}(\mathrm{P}=0.004)$ (Table 1$)$.

Cocaine-induced lethality was observed in $12 \%(n=3)$ of the dexmedetomidine group, $48 \%(n=12)$ of the alphamethyldopa group, $52 \%(n=13)$ of the moxonidine group and $72 \%(n=18)$ of the control group $(P<0.001)$. Dexme- detomidine was more protective than the placebo in terms of lethality $(\mathrm{P}<0.001)$. Cocaine-induced lethality was lower than the control (72\%) in the alpha-methyldopa (48\%) and moxonidine (52\%) groups (Table 1).

Figure 1 shows that all treatments prolonged (but not significantly) the time to seizure relative to placebo-treated mice $(P>0.05)$. In addition, the time to lethality was also significantly longer in the dexmedetomidine group (Figure 2, P $<0.001$ ).

\section{Discussion}

The present study demonstrated that pre-treatment with dexmedetomidine, alpha-methyldopa or moxonidine reduced seizure activity and lethality during acute cocaine toxicity. It is important to note that dexmedetomidine was the most protective of these compounds. This article was the first report about dexmedetomidine efficacy against cocaine-induced seizures and death. These results were partly compatible with the literature.

Unlike beta adrenergic antagonists and $\alpha 2$-AR antagonists, the $\alpha 2$-AR agonists were shown to decrease cocaine-dependent seizures and mortality $(23,24)$. Compatible with our study, Whittington et al. (14) showed that dexmedetomidine increased the cocaine dose needed to induce seizure activity, and the extracellular dopamine concentration in the nucleus ambiguus. In contrast to Mirski et al. (25) and Kubota et al. (26) in this study we observed that dexmedetomidine reduced seizure activity. These results suggest that the central sympatholytic and sedative properties of dexmedetomidine may make this drug a reasonable choice for acute cocaine poisoning treatment. Thus there have been a number of case reports where other more traditional agents have failed, while dexmedetomidine has been successfully used to manage hypertension and CNS excitability from withdrawal of cocaine and opioids (15). Recently, similar results have also been reviewed about poisoning with illicit (16).

Cocaine-dependent seizures were related to the stimulation of dopamine 1 receptors, thus dopamine 1 receptor antagonists decreased cocaine-dependent mortality (27). In addition, a similar study reported that dexmedetomidine has a sedative and analgesic effect (28).

It was reported that in a case of a 45 -year-old cocainedependent female patient, cocaine exposure conferred hypertension, which was decreased after dexmedetomi- 
dine (1 microgram/kg, 10 minutes) infusion, and mortality was avoided (15). In another study, Kersten et al. (12) reported that dexmedetomidine decreased morbidity and mortality related to cocaine toxicity. According to several studies based on the American Heart Association guidelines 2010, dexmedetomidine with its antihypertensive and bradycardic effects may be used to treat cocaine toxicity-related coronary syndrome instead of betaadrenergic blocking drugs (29-31).

Moxonidine is a central sympatholytic, central imidazoline (1I) receptor agonist, $\alpha 2$-AR agonist, and antihypertensive drug (6). Following a $1 \mathrm{mg} / \mathrm{kg}$ moxonidine injection into cocaine-dependent mice, there was a decrease in cocaine-related effects like locomotor activity without sedation (32). Alpha-methyldopa was shown to produce peripheral sympatho inhibition and antihypertensive effects by acting on the $\alpha 2$-AR in the pons and medulla oblongata (33). The side effects of alpha-methyldopa are greater than that of moxonidine in antihypertensive therapy. The sedative effect of alpha-methyldopa may ameliorate the agitation associated with cocaine toxicity.

Even though an accepted model was used in this study, we can only use these findings to support the safety and efficacy of these treatments for human studies. This study has a number of limitations. First, we could not determine whether there was any EEG evidence of ongoing seizures and epileptogenic activity (non-convulsive seizures) for logistical reasons. Thus, it is possible that some seizures may have been missed. Second, because no hemodynamic or electrocardiographic monitoring was carried out, the mechanism of death could not be determined. Third, it is possible that in some cases, cardiorespiratory arrest, death, and seizures were caused by the sedatives and were not related to cocaine intoxication. Last, even though this is an accepted model, there is a limitation related to the use of pre-treatment drugs with there being only one application route (i.e. injection).

In conclusion, the present study provides the first experimental evidence to support the use of dexmedetomidine for treating cocaine-induced toxicity. Premedication with dexmedetomidine reduced seizure activity during acute cocaine toxicity. In addition, dexmedetomidine seems to be effective in preventing cocaine-induced lethality. We suggest that further studies should be performed to evaluate the potential utility of dexmedetomidine for acute cocaine poisoning in humans.

\section{Authors' Contributions}

1-Study concept and design: Bulent Erdur and Selim Kortunay. 2-Acquisition of data: Murat Seyit. 3-Analysis and interpretation of data: Murat Seyit. 4-Drafting of the manuscript: Bulent Erdur and Selim Kortunay. 5-Critical revision of the manuscript for important intellectual content: Bulent Erdur and Selim Kortunay. 6-Statistical analysis: Ahmet Ergin. 7-Administrative, technical and material support: Aykut Yuksel, Atakan Yilmaz, Mert
Ozen, Aykut Uyanik, Onder Tomruk and Ahmet Ergin. 8-Study supervision: Bulent Erdur.

\section{Funding/Support}

This research was supported by a grant from the Pamukkale University, Faculty of Medicine Research Fund (PAU 817-2009).

\section{References}

1. Heard K, Cleveland NR, Krier S. Benzodiazepines and antipsychotic medications for treatment of acute cocaine toxicity in animal models--a systematic review and meta-analysis. Hum Exp Toxicol.2011;30(11):1849-54

2. Lippi G, Plebani M, Cervellin G. Cocaine in acute myocardial in farction. Adv Clin Chem. 2010;51:53-70.

3. Sharma HS, Muresanu D, Sharma A, Patnaik R. Cocaine-induced breakdown of the blood-brain barrier and neurotoxicity. Int Rev Neurobiol. 2009;88:297-334.

4. Devlin RJ, Henry JA. Clinical review: Major consequences of illicit drug consumption. Crit Care. 2008;12(1):202.

5. Mo W, Arruda JA, Dunea G, Singh AK. Cocaine-induced hypertension: role of the peripheral sympathetic system. Pharmacol Res. 1999;40(2):139-45.

6. Gresch PJ, Sved AF, Zigmond MJ, Finlay JM. Local influence of endogenous norepinephrine on extracellular dopamine in rat medial prefrontal cortex. J Neurochem.1995;65(1):111-6.

7. Yamamoto BK, Novotney S. Regulation of extracellular dopamine by the norepinephrine transporter. J Neurochem. 1998; 71(1):274-80.

8. Murai T, Yoshida Y, Koide S, Takada K, Misaki T, Koshikawa N, et al Clonidine reduces dopamine and increases GABA in the nucleus accumbens: an in vivo microdialysis study. Pharmacol Biochem Behav. 1998;60(3):695-701.

9. Delfs JM, Schreiber L, Kelley AE. Microinjection of cocaine into the nucleus accumbens elicits locomotor activation in the rat. $J$ Neurosci.1990;10(1):303-10.

10. Koob GF. Neural mechanisms of drug reinforcement. Ann N Y Acad Sci.1992;654:171-91.

11. Waselus M, Flagel SB, Jedynak JP, Akil H, Robinson TE, Watson SJ Long-term effects of cocaine experience on neuroplasticity in the nucleus accumbens core of addiction-prone rats. Neuroscience. 2013;248:571-84.

12. Kersten JR, Pagel PS, Hettrick DA, Warltier DC. Dexmedetomidine partially attenuates the sympathetically mediated systemic and coronary hemodynamic effects of cocaine. Anesth Analg 1995;80(1):114-21.

13. Menon DV, Wang Z, Fadel PJ, Arbique D, Leonard D, Li JL, et al Central sympatholysis as a novel countermeasure for cocaine-induced sympathetic activation and vasoconstriction in humans. $J$ Am Coll Cardiol. 2007;50(7):626-33.

14. Whittington RA, Virag L, Vulliemoz Y, Cooper TB, Morishima HO Dexmedetomidine increases the cocaine seizure threshold in rats. Anesthesiology. 2002;97(3):693-700.

15. Farag E, Chahlavi A, Argalious M, Ebrahim Z, Hill R, Bourdakos D, et al. Using dexmedetomidine to manage patients with cocaine and opioid withdrawal, who are undergoing cerebral angioplasty for cerebral vasospasm. Anesth Analg. 2006;103(6):1618-20.

16. Wong GT, Irwin MG. Poisoning with illicit substances: toxicology for the anaesthetist. Anaesthesia. 2013;68 Suppl 1:117-24.

17. Bousquet P, Dontenwill M, Greney H, Feldman J. I1-imidazoline receptors: an update. J Hypertens Suppl.1998;16(3):S1-5.

18. Ernsberger P, Graves ME, Graff LM, Zakieh N, Nguyen P, Collins LA, et al. I1-imidazoline receptors. Definition, characterization, distribution, and transmembrane signaling. Ann N Y Acad Sci. 1995;763:22-42.

19. Lione LA, Nutt DJ, Hudson AL. Characterisation and localisation of [3H]2-(2-benzofuranyl)-2-imidazoline binding in rat brain: a selective ligand for imidazoline I2 receptors. Eur J Pharmacol. 1998;353(1):123-35. 
20. Ruggiero DA, Regunathan S, Wang H, Milner TA, Reis DJ. Immunocytochemical localization of an imidazoline receptor protein in the central nervous system. Brain Res. 1998; 780(2):270-93.

21. Erdur B, Degirmenci E, Kortunay S, Yuksel A, Seyit M, Ergin A. Effects of pretreatment with etomidate, ketamine, phenytoin, and phenytoin/midazolam on acute, lethal cocaine toxicity. Neurol Res. 2012;34(10):952-6.

22. Yuksel A, Erdur B, Kortunay S, Ergin A. Assessment of propofol, midazolam and ziprasidone, or the combinations for the prevention of acute cocaine toxicity in a mouse model. Environ Toxicol Pharmacol. 2013;35(1):61-6.

23. O'Dell LE, George FR, Ritz MC. Antidepressant drugs appear to enhance cocaine-induced toxicity. Exp Clin Psychopharmacol. 2000;8(1):133-41.

24. Derlet RW, Albertson TE. Acute cocaine toxicity: antagonism by agents interacting with adrenoceptors. Pharmacol Biochem Behav.1990;36(2):225-31.

25. Mirski MA, Rossell LA, McPherson RW, Traystman RJ. Dexmedetomidine decreases seizure threshold in a rat model of experimental generalized epilepsy. Anesthesiology. 1994;81(6):1422-8.

26. Kubota T, Fukasawa T, Kitamura E, Magota M, Kato Y, Natsume J, et al. Epileptic seizures induced by dexmedetomidine in a neonate. Brain Dev. 2013;35(4):360-2.
27. Witkin JM, Newman AH, Nowak G, Katz JL. Role of dopamine D1 receptors in the lethal effects of cocaine and a quaternary methiodide analog. J Pharmacol Exp Ther.1993;267(1):266-74.

28. Coursin DB, Coursin DB, Maccioli GA. Dexmedetomidine. Curr Opin Crit Care. 2001;7(4):221-6.

29. Page R2, Utz KJ, Wolfel EE. Should beta-blockers be used in the treatment of cocaine-associated acute coronary syndrome? Ann Pharmacother. 2007;41(12):2008-13.

30. O'Connor RE, Brady W, Brooks SC, Diercks D, Egan J, Ghaemmaghami C, et al. Part 10: acute coronary syndromes: 2010 American Heart Association Guidelines for Cardiopulmonary Resuscitation and Emergency Cardiovascular Care. Circulation. 2010;122(18 Suppl 3):S787-817.

31. Vanden Hoek TL, Morrison LJ, Shuster M, Donnino M, Sinz E, Lavonas EJ, et al. Part 12: cardiac arrest in special situations: 2010 American Heart Association Guidelines for Cardiopulmonary Resuscitation and Emergency Cardiovascular Care. Circulation. 2010;122(18 Suppl 3):S829-61.

32. Smith RJ, Aston-Jones G. alpha(2) Adrenergic and imidazoline receptor agonists prevent cue-induced cocaine seeking. Biol Psychiatry. 2011;70(8):712-9.

33. van Zwieten PA. Antihypertensive drugs interacting with central imidazoline (I1)-receptors. Expert Opin Investig Drugs. 1998; 7(11):1781-93. 